\title{
Co-processing of Saturated and Unsaturated Triglycerides in Catalytic Cracking Process for Hydrocarbon Fuel Production
}

\author{
Iori Shimada ${ }^{1}$, Yoshitaka Nakamura ${ }^{2}$, Haruhisa Ohta ${ }^{3}$, \\ Kengo Suzuki ${ }^{3}$ and Toru TAKATsuka ${ }^{4}$ \\ ${ }^{1}$ Faculty of Textile Science and Technology, Shinshu University, 3-15-1 Tokida, Ueda-shi, \\ Nagano 386-8567, Japan \\ ${ }^{2}$ Graduate School of Science and Technology, Shinshu University, 3-15-1 Tokida, Ueda-shi, \\ Nagano 386-8567, Japan \\ ${ }^{3}$ Research \& Development Department, Euglena Co., Ltd., 75-1 Ono, Tsurumi-ku, Yokohama-shi, \\ Kanagawa 230-0046, Japan \\ ${ }^{4}$ Technology Development Unit, Chiyoda Corporation, 4-6-2 Minatomirai, Nishi-ku, Yokohama-shi, \\ Kanagawa 220-8766, Japan
}

Keywords: Plant Oils, Catalytic Cracking, Deoxygenation, Hydrogen Transfer Reaction, Renewable Fuel

\begin{abstract}
With the aim of the efficient use of plant oils as alternative fuels, the deoxygenation of saturated and unsaturated triglycerides in a catalytic cracking process was investigated using a fluid catalytic cracking catalyst with enhanced hydrogentransfer activity. The decomposition and deoxygenation of sunflower oil (unsaturated triglycerides) proceeded rapidly and produced a large amount of aromatic hydrocarbons, which are unsuitable for fuel applications. In contrast, the rate of deoxygenation of coconut oil (saturated triglycerides) was slow and some oxygen-containing species were observed as products. During the co-processing of saturated and unsaturated triglycerides, the deoxygenation of saturated triglycerides was accelerated and complete deoxygenation was achieved. The acceleration of the deoxygenation reaction was attributed to the rapid formation of hydrogen donors, such as olefins and naphthenes, from the decomposition of unsaturated triglycerides. The olefins and naphthenes released hydrogen species by cyclization and aromatization reactions. These hydrogen species then reacted with saturated triglycerides and their derivatives (fatty acids and aldehydes) in hydrogen-transfer reactions, accelerating the hydrodeoxygenation of saturated triglycerides. The hydrodeoxygenation of saturated triglycerides produced paraffins and olefins rather than aromatics. The increase in the amount of paraffins and olefins produced by the accelerated deoxygenation of saturated triglycerides was larger than the amount of aromatic hydrocarbons derived from unsaturated triglycerides. Thus, co-processing of saturated and unsaturated triglycerides was confirmed to be effective for simultaneously achieving both the acceleration of saturated triglyceride deoxygenation and the suppression of aromatic hydrocarbon formation.
\end{abstract}

\section{Introduction}

Plant oils are attracting much attention as alternatives to fossil fuels because they can be extracted from various resources such as inedible crops and waste cooking oils (Sinthupinyo et al., 2010). They consist mainly of triglycerides and can be upgraded to alternative automotive fuels by chemical conversion processes such as transesterification (Tsuchiya et al., 2011; Kwon et al., 2012), hydrocracking (Kubičková and Kubička, 2010) and catalytic cracking (Huber and Corma, 2007; Taufiqurrahmi and Bhatia, 2011). Among these technologies, we focus here on catalytic cracking, which can convert triglycerides into hydrocarbons without requiring a hydrogen atmosphere. The deoxygenation of triglycerides and their conversion to hydrocarbons is important for alternative fuels because oxygen-containing

Received on June 1, 2017; accepted on November 8, 2017 DOI: $10.1252 /$ jcej. 17 we187

Correspondence concerning this article should be addressed to I. Shimada (E-mail address: iori@shinshu-u.ac.jp).

Presented at The 5th ASCON-IEEChE 2016 at Yokohama, November 2016 fuels have lower energy densities and poorer thermal and oxidation stabilities (Hosokai et al., 2014; Inaba et al., 2014). Deoxygenation with a catalytic cracking process, therefore, offers the possibility of a relatively cheap method to produce high quality hydrocarbon fuels from biomass resources if the process does not involve a costly hydrogen atmosphere.

In the catalytic cracking of triglycerides, the rate and selectivity of the deoxygenation reaction and the composition of the hydrocarbon products depend on the structure of the feedstocks. Deoxygenation and decomposition of unsaturated triglycerides proceed rapidly, but the products contain large amounts of polyaromatics, which are unsuitable for fuel applications (Dupain et al., 2007; Melero et al., 2010). In contrast, the catalytic cracking of saturated triglycerides produces more paraffins and olefins than aromatics, but the deoxygenation proceeds slowly and must be accelerated to achieve an efficient conversion of plant oils to hydrocarbon fuels (Shimada et al., 2017). To understand the difference in deoxygenation rate for saturated and unsaturated triglycerides, we previously focused on the impact of the hydrogentransfer reaction (Shimada et al., 2017), a bimolecular reaction that proceeds in the catalytic cracking process. Here, hydrogen species are released from a hydrogen donor and 
received by a hydrogen acceptor. During catalytic cracking, unsaturated carbon chains in triglycerides easily form carbenium ions at Brønsted acid sites, resulting in consecutive $\beta$ scissions and hydrogen-transfer reactions. Hydrogen species are released during the cracking, cyclization and aromatization of the carbon chains. These hydrogen species can be used to accelerate the deoxygenation of ester bonds in the feedstock molecules. In contrast, saturated carbon chains are more stable than unsaturated ones; therefore, the hydrogentransfer reaction for ester bonds is suppressed during the catalytic cracking of saturated triglycerides. Thus, the activity of the hydrogen-transfer reaction significantly affects the reaction rate and selectivity of triglyceride deoxygenation.

Because the hydrogen-transfer reaction is bimolecular, strong hydrogen donors or acceptors can affect reactions of other feedstocks when they are co-processed in the catalytic cracking reaction. Doronin et al. (2013) investigated the synergetic effect of unsaturated triglycerides and vacuum gas oil (VGO) in a co-processing catalytic cracking reaction. Olefins produced from the unsaturated triglycerides were converted to carbenium ions, and interacted with paraffinic and naphthenic hydrocarbons contained in the VGO. The hydrogen-transfer reaction promoted the activation of the paraffinic and naphthenic hydrocarbons, and resulted in an enhanced VGO conversion. However, the effect of co-processing during the catalytic cracking reaction on the deoxygenation of triglycerides has, insofar as we are aware, not been reported. If the hydrogen species released during the cracking of unsaturated triglycerides followed by cyclization and aromatization reactions can be transferred to saturated triglycerides in co-processing catalytic cracking, the deoxygenation of saturated triglycerides may be accelerated. In this study, we, therefore, investigate the synergetic effects of saturated and unsaturated triglycerides in the catalytic cracking reaction with the object of accelerating the deoxygenation of saturated triglycerides and improving the yield of desired hydrocarbon products.

\section{Experimental}

\subsection{Materials}

An equilibrium catalyst (E-cat) was obtained from a commercial residual fluid catalytic cracking unit and used for all the catalytic cracking experiments. The plant oil feedstocks were coconut oil (Kaneda Shoji Co., Ltd.) and sunflower oil (Wako Pure Chemical Industries, Ltd.). Coconut oil consists mainly of saturated $\mathrm{C}_{12}$ and $\mathrm{C}_{14}$ fatty acids $(46.9 \mathrm{~mol} \%$ and $15.7 \mathrm{~mol} \%$, respectively), while sunflower oil is mainly unsaturated $\mathrm{C}_{18}$ fatty acids $(88.5 \mathrm{~mol} \%)$. We have previously reported detailed fatty acid compositions of the plant oils used (Shimada et al., 2017). We also used two model triglycerides: trilaurin (a saturated triglyceride composed of $\mathrm{C}_{12}$ fatty acids; Tokyo Chemical Industry Co., Ltd.) and triolein (an unsaturated triglyceride composed of $\mathrm{C}_{18}$ fatty acids with a single double bond; Wako Pure Chemical Industries, Ltd.).

\subsection{Catalytic cracking test}

Catalytic activity tests were conducted in a fixed-bed microactivity test reactor, the details of which are given elsewhere (Shimada et al., 2015a). In each trial, E-cat (2.7-8.0 g) was placed in the reactor, which was maintained at $470^{\circ} \mathrm{C}$. The feedstock (a coconut oil/sunflower oil mixture or a trilaurin/triolein mixture) was electrically preheated before being fed into the reactor by a microfeeder. The feed injection time was $75 \mathrm{~s}$ and the weight hourly space velocity (WHSV) was varied between 12 and $24 \mathrm{~h}^{-1}$. For these conditions, the weight ratio of the catalyst to the oil (cat/oil) was in the range of 2-4. $\mathrm{N}_{2}$ gas was added during feed injection at $19 \mathrm{~mL} \mathrm{~min}^{-1}$. After each test, the catalyst was stripped by purging with $\mathrm{N}_{2}$ for $15 \mathrm{~min}$. During the reaction and stripping stages, the liquid products were collected in a cold trap with two receiving vessels connected in series and maintained at 0 and $-15^{\circ} \mathrm{C}$, respectively. Simultaneously, the gaseous products were collected in a gas burette by displacement of a saturated $\mathrm{NaCl}$ solution. For all experiments, the mass balance across the collected products was found to be in the range of $94-108 \mathrm{wt} \%$ of the process inputs.

The amounts of $\mathrm{H}_{2}, \mathrm{~N}_{2}, \mathrm{CO}_{2}$ and $\mathrm{CO}$ in the gaseous products were determined using a gas chromatograph (GC) system (GC-8A, Shimadzu Corp.) equipped with a packed column (SHINCARBON-ST 50/80, Shinwa Chemical Industries, Ltd.) and a thermal conductivity detector (TCD), with Ar as the carrier gas. Gaseous hydrocarbons, liquid hydrocarbons and oxygenates in the liquid products were analyzed with another GC system (GC-2014, Shimadzu Corp.) fitted with a capillary column (BP1, SGE Analytical Science Pty. Ltd.) and a flame ionization detector (FID), with $\mathrm{He}$ as the carrier gas. Biphenyl (99.5\%, Sigma-Aldrich Co.) was used as the internal standard in the GC-FID assay. Quantification of the hydrocarbons and oxygenates was based on the effective carbon number approach (Sternberg et al., 1962). Fourier-transform infrared (FTIR) spectra of the liquid products were also recorded on a FTIR spectrometer (FT/IR-4200, JASCO Corp.) using a liquid membrane method with a $\mathrm{KBr}$ window. The amount of coke deposited on the catalyst was determined from the difference between the mass of the reactor before and after testing. Three hydrocarbon fractions were defined based on carbon number or boiling point thresholds: gaseous hydrocarbons $\left(\mathrm{C}_{1}-\mathrm{C}_{4}\right)$, gasoline $\left(\mathrm{C}_{5}-216^{\circ} \mathrm{C}\right)$ and jet fuel $\left(\mathrm{C}_{10}-\mathrm{C}_{15}\right)$.

\section{Results}

\subsection{Co-processing of coconut oil and sunflower oil}

The catalytic cracking of several coconut oil/sunflower oil blends with different mixing ratios was investigated. Figures 1(a) and (b) show the yields of hydrocarbons, oxygenates, $\mathrm{CO}_{2}, \mathrm{CO}$ and coke for the different blends. In addition to these reaction products, water droplets were visible in the liquid products, though the amount of water produced was not quantified. Fatty acids, ketones, aldehydes and esters were detected as oxygenates, but triglycerides were not detected in any reaction products from any of the experiments. 

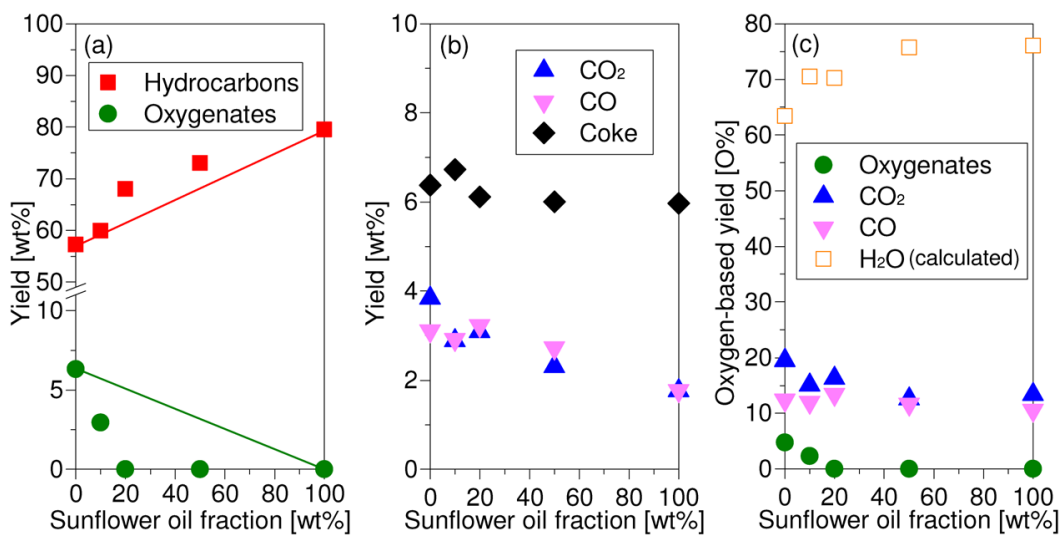

Fig. 1 Product yields from the catalytic cracking of various coconut oil/sunflower oil blends $\left(470^{\circ} \mathrm{C}, \mathrm{WHSV}=16 \mathrm{~h}^{-1}\right)$; (a) weight-based yields of hydrocarbons and oxygenates; (b) weight-based yields of $\mathrm{CO}_{2}, \mathrm{CO}$ and coke; (c) oxygen-based yields of oxygenates, $\mathrm{CO}_{2}, \mathrm{CO}_{\text {and }} \mathrm{H}_{2} \mathrm{O}$; lines in (a) correspond to theoretical additive values for the two oils assuming no interaction; deviations from these lines suggest interactions occurred between the two oils; oxygen-based yield of $\mathrm{H}_{2} \mathrm{O}$ in (c) was calculated from oxygen balance.

Thus, the conversion of triglycerides was assumed to be $100 \%$. Hydrocarbons were the main reaction products in all of the experiments. Increasing the sunflower oil fraction in the feed blend increased the yield of hydrocarbons but decreased the yields of oxygenates, $\mathrm{CO}_{2}$ and $\mathrm{CO}$. Changing the blend of oils in the feedstock appeared to have little impact on the coke yield.

Figure 1(c) shows the oxygen-based yields of oxygenates, $\mathrm{CO}_{2}$ and $\mathrm{CO}$. The yields of oxygenates and $\mathrm{CO}_{2}$ decreased as the fraction of sunflower oil was increased. Although we could not quantify the degree of water formation, we estimated this by assuming that all oxygen atoms in the feedstock were converted to the detected oxygenates, $\mathrm{CO}_{2}$, $\mathrm{CO}$ and water. With this assumption, an oxygen balance suggested that the water yields derived from the results in Figure 1(c) were 63-76 O\% (plotted with open squares), which corresponded to weight-based yields of $8-11 \mathrm{wt} \%$. The total yields of hydrocarbons, oxygenates, $\mathrm{H}_{2}, \mathrm{CO}_{2}, \mathrm{CO}$, coke and water (calculated value) corresponded to a mass that was $86-97 \%$ of the value required to close the mass balance, largely verifying our assumption on the conversion of feedstock oxygen atoms. Therefore, Figure 1(c) suggests that the ratio of the oxygen atoms removed as water increased with the mass fraction of sunflower oil in the blend.

For reactions with coconut oil/sunflower oil blends, the oxygenate yields were lower than the sum of the contributions expected from the individual components. In particular, no oxygenates were detected in the products from reactions with feedstocks with $20 \mathrm{wt} \%$ or more sunflower oil. This decrease in oxygenate yield was accompanied by an increase in the yield of hydrocarbons, the combined value of which was larger than that calculated by adding the contributions from the individual constituents. These deviations from the expected values implied interactions occurred between the two oils. In contrast, the yields of $\mathrm{CO}_{2}, \mathrm{CO}$ and coke showed a linear trend with the fraction of sunflower oil in the feedstock. This suggested that adding sunflower oil to the blend accelerated the deoxygenation of coconut oil and water formation but did not accelerate the formation of

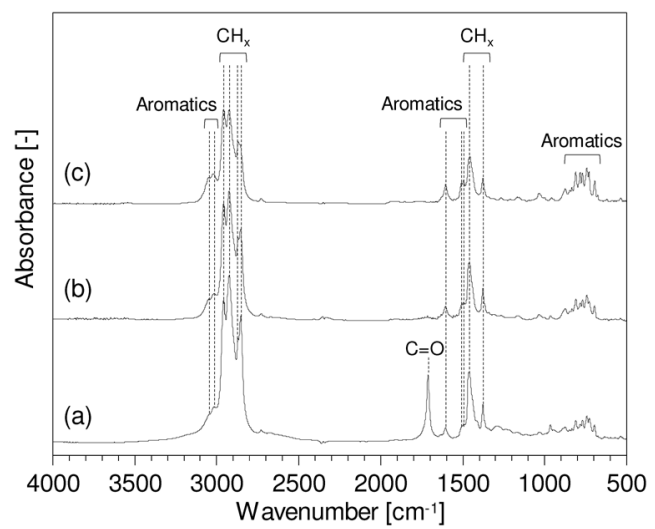

Fig. 2 FTIR spectra of the liquid products from the catalytic cracking of (a) coconut oil, (b) coconut oil/sunflower oil blend $(80 / 20 \mathrm{wt} \%)$, and $(\mathrm{c})$ sunflower oil $\left(470^{\circ} \mathrm{C}, \mathrm{WHSV}=16 \mathrm{~h}^{-1}\right)$

\section{$\mathrm{CO}_{2}, \mathrm{CO}$ or coke.}

The FTIR spectra shown in Figure 2 support the observation that deoxygenation of coconut oil was accelerated by adding sunflower oil. A characteristic peak at $1711 \mathrm{~cm}^{-1}$, which corresponds to $\mathrm{C}=\mathrm{O}$ bond-stretching vibrations, was observed in the products from the cracking of coconut oil but had disappeared in co-processing with $20 \mathrm{wt} \%$ sunflower oil. The intensity of peaks at 1378, 1465, 2855, 2872, 2926, and $2956 \mathrm{~cm}^{-1}$, which are attributed to aliphatic $\mathrm{CH}_{2}$ and $\mathrm{CH}_{3}$ groups in paraffins and olefins (denoted as $\mathrm{CH}_{x}$ in the figure), decreased with increases in the proportion of sunflower oil in the feed blend. In contrast, the intensities of characteristic peaks of aromatic hydrocarbons at 670-890, $1493,1505,1605,3020$ and $3050 \mathrm{~cm}^{-1}$ increased with the amount of sunflower oil in the feed, suggesting that the aromatization of hydrocarbons was enhanced by adding sunflower oil. The enhancement of aromatization reactions was also confirmed by the hydrogen balance, because the formation of aromatics during catalytic cracking is accompanied by the release of hydrogen species. Indeed, the $\mathrm{H}_{2}$ yield from the catalytic cracking of sunflower oil was $0.018 \mathrm{wt} \%$, which 

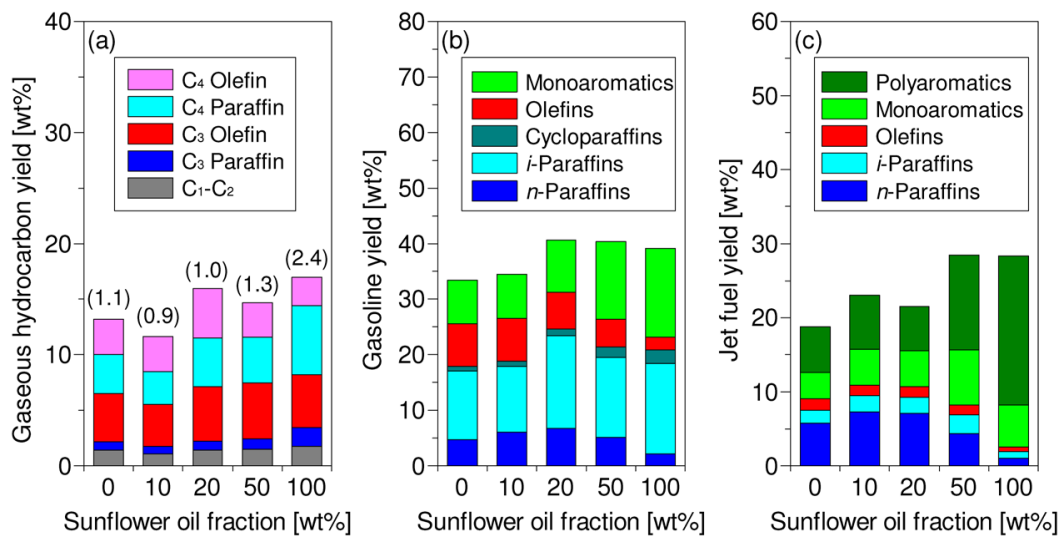

Fig. 3 Yields and compositions of the (a) gaseous, (b) gasoline and (c) jet fuel hydrocarbon fractions from the catalytic cracking of various coconut oil/sunflower oil blends $\left(470^{\circ} \mathrm{C}\right.$, WHSV $\left.=16 \mathrm{~h}^{-1}\right)$; numbers in parentheses above the chart in (a) represent the $\mathrm{C}_{4}$ paraffin/C4 olefin ratio

was higher than that from coconut oil $(0.011 \mathrm{wt} \%)$. Furthermore, hydrogen species released during aromatization reactions have a strong hydrogenation ability during catalytic cracking (Shimada et al., 2015b). Therefore, Figure 2 suggests that unsaturated triglycerides can function as strong hydrogen donors during the catalytic cracking reaction.

Figure 3 shows the hydrocarbon yields for the gaseous, gasoline and jet fuel fractions, and their compositions. For the gaseous fraction, increasing the proportion of sunflower oil in the feed increased the yields of $\mathrm{C}_{3}$ and $\mathrm{C}_{4}$ paraffins but decreased those of $\mathrm{C}_{3}$ and $\mathrm{C}_{4}$ olefins. Figure 3(a) also presents the $\mathrm{C}_{4}$ paraffin/ $\mathrm{C}_{4}$ olefin ratio, which is an index of hydrogen-transfer activity during hydrocarbon cracking: a high $\mathrm{C}_{4}$ paraffin $/ \mathrm{C}_{4}$ olefin ratio in the reaction products indicates a significant hydrogen-transfer reaction (Potapenko et al., 2016). The $\mathrm{C}_{4}$ paraffin $/ \mathrm{C}_{4}$ olefin ratio remained largely constant and near unity for small sunflower oil fractions $(<20 \mathrm{wt} \%)$, but increased drastically for larger sunflower oil fractions. Here, the regions with 'small' and 'large' sunflower oil fractions correspond to the accelerated deoxygenation region and the complete deoxygenation region in Figure 1, respectively. Thus, it can be concluded that different types of hydrogen-transfer reaction proceeded in the two regions.

The maximum total gasoline yield occurred when the feed contained $20 \mathrm{wt} \%$ sunflower oil, which corresponded to the boundary of the accelerated deoxygenation region and the complete deoxygenation region. Changes in the gasoline composition brought about by the addition of sunflower oil were completely different in the two regions. In the accelerated deoxygenation region (sunflower oil $<20 \mathrm{wt} \%$ ), the addition of sunflower oil increased the yield of paraffins in the gasoline fraction. In contrast, in the complete deoxygenation region (sunflower oil $>20 \mathrm{wt} \%$ ), adding sunflower oil increased the yield of aromatics and decreased the yield of paraffins and olefins. Similar trends were observed in the jet fuel fraction: the jet fuel fraction in the accelerated deoxygenation region contained paraffins, while that in the complete deoxygenation region was dominated by polyaromatics. These results corroborate the results obtained from the FTIR spectra shown in Figure 2. Moreover, Figure 3
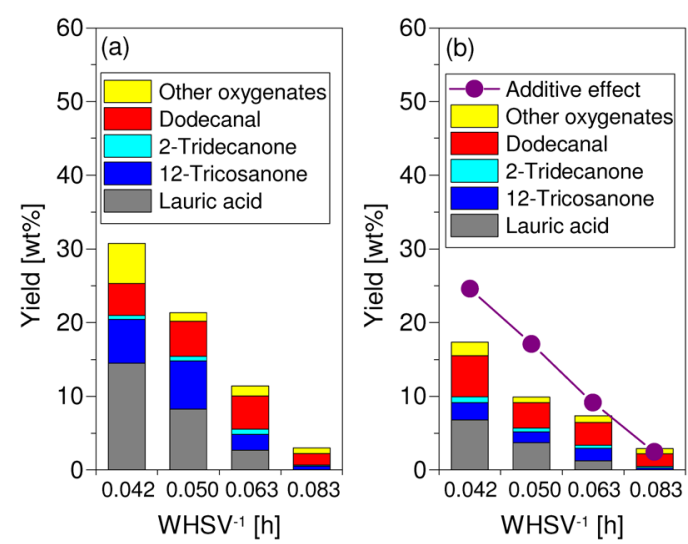

Fig. 4 Oxygenate yields from the catalytic cracking of (a) trilaurin and (b) a trilaurin/triolein blend (80/20 wt\%) for different residence times $\left(470^{\circ} \mathrm{C}\right)$

confirms that the addition of unsaturated triglycerides to saturated triglycerides produced different effects in the accelerated deoxygenation and the complete deoxygenation regions. High yields of gasoline and jet fuel fractions with low aromatics content could be obtained at the boundary between the two regions, which corresponded to approximately $20 \mathrm{wt} \%$ of sunflower oil in the feed in the present work.

\subsection{Co-processing of saturated and unsaturated model triglycerides}

To clarify the synergetic effects of saturated and unsaturated triglycerides in the deoxygenation reaction, the catalytic cracking of a trilaurin/triolein mixture was also investigated in detail. Figure 4 shows the oxygenate yields from the catalytic cracking of trilaurin and a trilaurin/triolein blend for different residence times. In both experiments, the detected oxygenates were mainly lauric acid ( $\mathrm{a}_{12}$ fatty acid), 12-tricosanone (a $\mathrm{C}_{23}$ ketone), 2-tridecanone (a $\mathrm{C}_{13}$ ketone) and dodecanal (a $\mathrm{C}_{12}$ aldehyde). These compounds were typical reaction products from the catalytic cracking of trilaurin (a $\mathrm{C}_{12}$ triglyceride) (Shimada et al., 2017). However, 

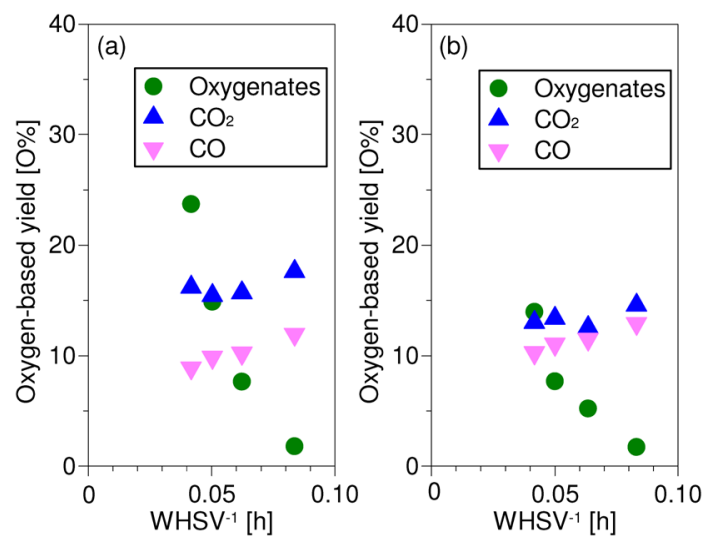

Fig. 5 Oxygen-based yields of oxygenates, $\mathrm{CO}_{2}$ and $\mathrm{CO}$ from the catalytic cracking of (a) trilaurin and (b) a trilaurin/triolein blend $(80 / 20 \mathrm{wt} \%)$ for different residence times $\left(470^{\circ} \mathrm{C}\right)$
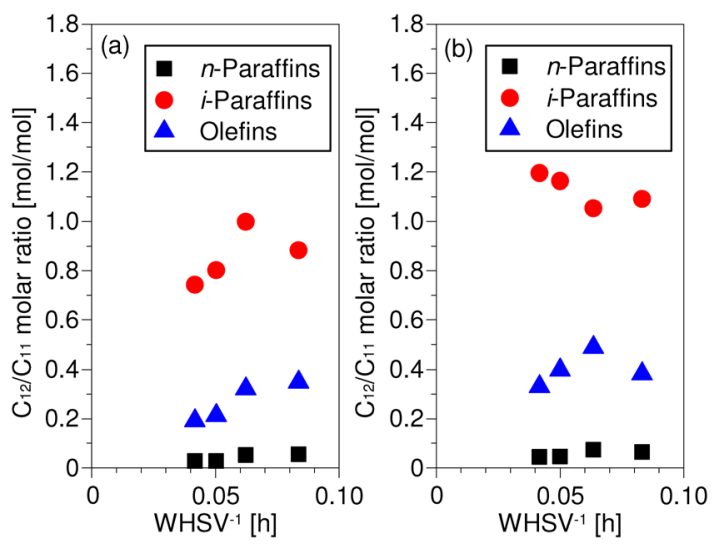

Fig. 6 Molar ratio of $\mathrm{C}_{12} n$-paraffin/C11 n-paraffin (black squares), $\mathrm{C}_{12} i$-paraffins $/ \mathrm{C}_{11} i$-paraffins (red circles) and $\mathrm{C}_{12}$ olefins $/ \mathrm{C}_{11}$ olefins (blue triangles) in the reaction products from the catalytic cracking of (a) trilaurin and (b) a trilaurin/triolein blend $(80 / 20 \mathrm{wt} \%)$ for different residence times $\left(470^{\circ} \mathrm{C}\right)$

the oxygenates derived from triolein were barely observed in the products from the cracking of the trilaurin/triolein mixture, suggesting the rapid deoxygenation of unsaturated triglycerides. The total oxygenate yield from the cracking of the trilaurin/triolein mixture was lower than that calculated by simply adding the values from the constituent feed components. This suggested a synergetic effect between trilaurin and triolein during the deoxygenation reaction; this was especially the case for reactions with short residence times. Adding triolein also changed the composition of the produced oxygenates: those produced from the cracking of trilaurin mainly consisted of lauric acid and 12-tricosanone; whereas, those produced from the mixture included a large proportion of dodecanal. This suggested that adding unsaturated triglycerides changed the selectivity in trilaurin's deoxygenation pathway.

To confirm changes in the selectivity of the reaction pathway, we investigated the deoxygenation products. Figure 5 shows the oxygen-based yields of oxygenates, $\mathrm{CO}_{2}$ and $\mathrm{CO}$ from the catalytic cracking of trilaurin and a trilaurin/triole- in mixture. In both cases, the increase in $\mathrm{CO}_{2}$ and $\mathrm{CO}$ yields were modest compared to the drastic decrease in the yield of the oxygenates. This suggests that most oxygen atoms in the feed were removed as $\mathrm{H}_{2} \mathrm{O}$. In addition, the catalytic cracking of the trilaurin/triolein mixture resulted in a lower oxygen-based yield of $\mathrm{CO}_{2}$ than that for trilaurin alone, which suggested that adding triolein suppressed $\mathrm{CO}_{2}$ formation and accelerated $\mathrm{H}_{2} \mathrm{O}$ formation. Figure 6 shows the molar ratios of $\mathrm{C}_{12}$ hydrocarbons $/ \mathrm{C}_{11}$ hydrocarbons for the reaction products. The ratios from the trilaurin/triolein mixture were higher than those from trilaurin alone, which was especially obvious for $i$-paraffins and olefins. The increase in the $\mathrm{C}_{12} / \mathrm{C}_{11}$ ratios can be attributed not only to the reaction products from triolein cracking, but also to a change in the selectivity of the reaction pathway in trilaurin cracking because the observed $\mathrm{C}_{12} / \mathrm{C}_{11}$ ratios from the cracking of the trilaurin/triolein mixture were higher than those calculated by summing the values from the individual components (e.g., $0.055,0.89$ and 0.34 for $n$-paraffins, $i$-paraffins and olefins, respectively, at $\mathrm{WHSV}^{-1}=0.063 \mathrm{~h}$ ). Here, $\mathrm{C}_{11}$ paraffins and olefins were the products from decarboxylation or decarbonylation reactions; whereas, $\mathrm{C}_{12}$ paraffins and olefins were produced by hydrodeoxygenation reactions. Thus, the increase in $\mathrm{C}_{12} / \mathrm{C}_{11}$ ratios is consistent with the increase in $\mathrm{H}_{2} \mathrm{O} / \mathrm{CO}_{2}$ ratios observed in Figure 5. Relatedly, we previously reported that the catalytic cracking of dodecanal gave a lower $\mathrm{CO}_{2}$ yield and a higher $\mathrm{C}_{12} / \mathrm{C}_{11}$ ratio than those obtained for trilaurin and lauric acid (Shimada et al., 2017). We, therefore, concluded that the hydrodeoxygenation pathway in the catalytic cracking of trilaurin includes dodecanal formation. Considering this, the results shown in Figures 4-6 suggest that adding triolein to trilaurin during the catalytic cracking reaction accelerated the hydrodeoxygenation pathway that proceeded via aldehyde formation.

\section{Discussion}

The reaction mechanism for triglyceride deoxygenation during catalytic cracking (Figure 7) with zeolite catalysts has been reported in the literature. In the initial reaction (R1), triglycerides are converted to two fatty acids, aldoketene and acrolein (Chang and Wan, 1947). The aldoketene is so reactive that it was not detected in our experiments. Meanwhile, acrolein decomposes to olefins such as propylene, aromatizes via a Diels-Alder reaction, and polymerizes to form coke (Corma et al., 2008). The deoxygenation of fatty acids to jet-fuel-range paraffins and olefins proceeds via three pathways: direct decarboxylation (R2), ketonic decarboxylation (R3-R5) and hydrodeoxygenation (R6-R8) (Shimada et al., 2017). Ketones and aldehydes are the intermediates in the ketonic decarboxylation and hydrodeoxygenation pathways, respectively. The direct decarboxylation and the ketonic decarboxylation form $\mathrm{CO}_{2}$ or $\mathrm{CO}$; whereas, the hydrodeoxygenation produces $\mathrm{H}_{2} \mathrm{O}$. The hydrodeoxygenation pathway is deemed efficient because all of the carbon in the feedstock is converted to hydrocarbons. The hydrodeoxygenation reaction under catalytic cracking 


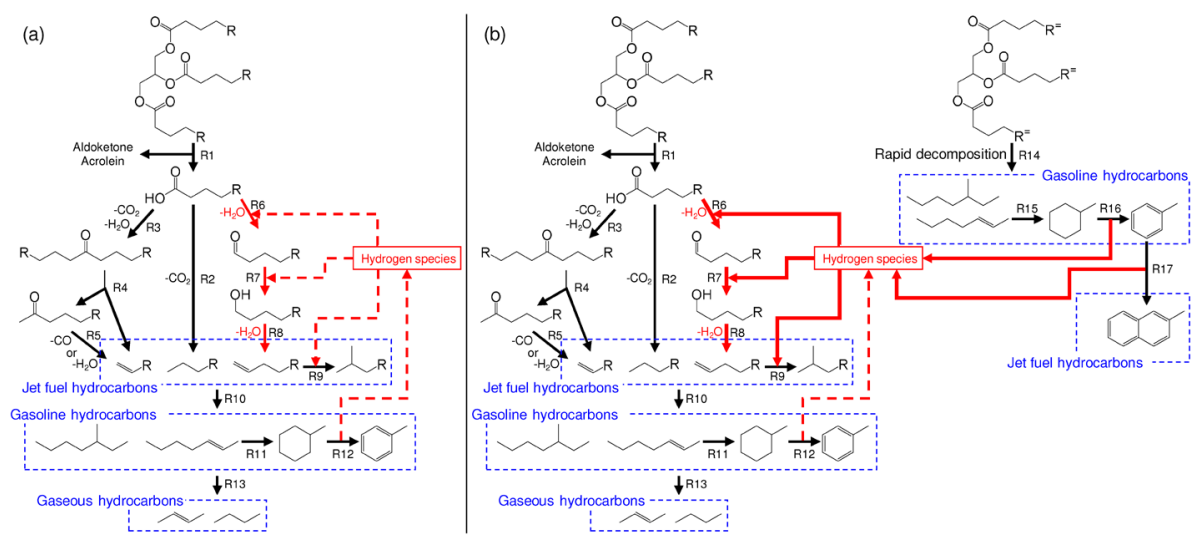

Fig. 7 Schematic diagram of the deoxygenation reaction mechanism during the catalytic cracking of (a) saturated triglycerides and (b) a blend of saturated/unsaturated triglycerides with a small unsaturated triglyceride fraction; red arrows represent the hydrogen-transfer-reaction pathway; $\mathrm{R}$ and $\mathrm{R}^{=}$represent saturated and unsaturated carbon chains, respectively

conditions (i.e., a hydrogen-free atmosphere) proceeds via a hydrogen-transfer reaction with a hydrogen donor (Černý et al., 2013). In the present work, the hydrogen donors should be olefins and naphthenes that are produced by the cracking of jet-fuel-range paraffins and olefins (R10). Such olefins and naphthenes release hydrogen species by cyclization and aromatization reaction (R11-R12). These species are then received by oxygenates (fatty acids and aldehydes) to produce water (R6 and R7). However, during the catalytic cracking of saturated triglycerides, the cracking of saturated carbon chains does not proceed rapidly and the amount hydrogen species released is small. Therefore, the hydrodeoxygenation pathway is relatively uncompetitive.

Figure 7(b) shows the reaction mechanism for the cracking of the blend of saturated/unsaturated triglycerides with a small unsaturated triglyceride fraction (representing, for example, the reactions for blends with sunflower oil $<20 \mathrm{wt} \%$ shown in Figures 1-3, or 'the accelerated deoxygenation region'). Unsaturated triglycerides are deoxygenated and cracked more rapidly than saturated triglycerides (R14) because the unsaturated carbon chains easily form carbenium ions at Brønsted acid sites, resulting in consecutive $\beta$ scissions and hydrogen-transfer reactions (Gates et al., 1979). We propose that the cracking of unsaturated carbon chains proceeded at least as fast as the decomposition of ester bonds because $\mathrm{C}_{17}$ and $\mathrm{C}_{18}$ paraffins and olefins were hardly observed as reaction products from the catalytic cracking of triolein. Therefore, few jet-fuel-range paraffins and olefins were produced by cracking unsaturated triglycerides; gasoline-range paraffins, olefins and naphthenes were produced instead. These latter compounds act as hydrogen donors by releasing hydrogen species during cyclization and aromatization reactions (R15-R16) with released hydrogen species then able to react with unsaturated triglycerides and also with saturated triglycerides and their derivatives (fatty acids and aldehydes). Therefore, the hydrodeoxygenation pathway for saturated triglycerides via aldehyde formation (R6-R8) was accelerated by adding unsaturated triglycerides (Figures 4-6). The formation of the hydrogen donor from the unsaturated triglycerides proceeded so rapidly that the accel- eration of the deoxygenation of saturated triglycerides was the dominant impact on reactions of short residence times, as shown in Figure 4. Here, the linear olefins produced by the hydrodeoxygenation reaction easily formed carbenium ions and isomerized to branched ions, which were converted to branched paraffins by a hydrogen-transfer reaction (R9). Hence, the $\mathrm{C}_{12} / \mathrm{C}_{11}$ ratios for $i$-paraffins and olefins, rather than $n$-paraffins, were increased by adding triolein to trilaurin (Figure 6). In the case of plant oils, accelerating the deoxygenation of coconut oil by adding sunflower oil increased the yield of paraffins in the jet fuel fraction $\left(\mathrm{C}_{10^{-}}\right.$ $\mathrm{C}_{15}$ ) (Figure 3(c)) because coconut oil mainly contains saturated $\mathrm{C}_{12}$ and $\mathrm{C}_{14}$ fatty acids. The cracking of the carbenium ions also occurred and produced paraffins and olefins in the gasoline fraction (Figure 3(b)). Although any added unsaturated triglycerides may have been converted to polycyclic aromatic hydrocarbons (R17), the amount of unsaturated triglycerides was so small that any increase in polycyclic aromatic hydrocarbons was negligible because of the large increase in the production of paraffins and olefins from the accelerated deoxygenation of saturated triglycerides. In addition, the gaseous- and gasoline-fraction olefins were not hydrogenated to paraffins despite the activation of the hydrogen-transfer reaction caused by adding unsaturated triglycerides (Figures 3(a) and (b)). This suggested that the hydrogen species were preferentially consumed by oxygenates rather than by olefins, and resulted in the production of a high octanerated gasoline despite the activation of the hydrogen-transfer reaction.

However, for the cracking of a blend of saturated/unsaturated triglycerides with a large unsaturated triglyceride fraction (representing, for example, the reactions for blends with sunflower oil $>20 \mathrm{wt} \%$ shown in Figures $1-3$, or 'the complete deoxygenation region'), the hydrogen-donating ability of unsaturated triglycerides was higher than that required for the deoxygenation of saturated triglycerides. Because the addition of unsaturated triglycerides was unable to further accelerate the deoxygenation of saturated triglycerides, the increase in the proportion of unsaturated triglycerides in the feed simply increased the fraction of 
products derived from unsaturated triglycerides (monoaromatics and polyaromatics) and decreased the fraction derived from saturated triglycerides (paraffins and olefins). Furthermore, excess unsaturated triglycerides readily produced carbenium ions, which interacted with paraffins via hydrogen-transfer reactions. This activated the paraffins (converted them to carbenium ions) and resulted in cyclization and aromatization to produce aromatics, or cracking to produce gaseous hydrocarbons. Therefore, the yield of aromatic hydrocarbons increased and the yield of paraffins and olefins decreased in the gasoline and jet fuel fractions as the proportion of unsaturated triglycerides in the feed blend was increased (Figures 3(b) and (c)). In addition, excess hydrogen species converted olefins in the gaseous and gasoline fractions to paraffins, as confirmed by the increase of the $\mathrm{C}_{4}$ paraffins $/ \mathrm{C}_{4}$ olefins ratio shown in Figure 3(a).

Considering the above, the acceleration of the deoxygenation of saturated triglycerides and the suppression of the formation of polycyclic aromatic hydrocarbons from unsaturated triglycerides can be achieved by co-processing saturated and unsaturated triglycerides in the catalytic cracking process by controlling the feed composition and the activity of the hydrogen-transfer reaction.

\section{Conclusions}

The synergetic effects of saturated and unsaturated triglycerides in the catalytic cracking process were investigated. Reactions using saturated and unsaturated triglycerides individually both exhibit unwanted properties: the slow deoxygenation of saturated triglycerides and the formation of polycyclic aromatic hydrocarbons from unsaturated triglycerides. During the co-processing of saturated and unsaturated triglycerides, the decomposition of unsaturated triglycerides proceeded rapidly and produced hydrogen donors such as olefins and naphthenes. These hydrogen donors were able to react with saturated triglycerides and their derivatives (fatty acids and aldehydes) via hydrogen-transfer reactions, accelerating the hydrodeoxygenation of saturated triglycerides. Although the hydrogen donors may be converted to aromatic hydrocarbons, the amount of unsaturated triglycerides necessary for complete deoxygenation of saturated triglycerides was so small that the increase in the yield of aromatic hydrocarbons was considered negligible compared to the increase in the yields of paraffins and olefins, which were produced from the accelerated deoxygenation of saturated triglycerides. Thus, the deoxygenation rate and the hydrocarbon product composition may be controlled independently without incurring trade-offs from the coprocessing of saturated and unsaturated triglycerides in the catalytic cracking process. The acceleration of the deoxygenation of saturated triglycerides and the suppression of polycyclic aromatic hydrocarbon formation from unsaturated triglycerides can be achieved simultaneously by employing an appropriate blending ratio and by controlling the activity of the hydrogen-transfer reactions.

\section{Acknowledgement}

Part of this work was financially supported by JSPS KAKENHI Grant Number JP15K21038 and JGC-S Scholarship Foundation. We thank Sam Pickard, PhD, from Edanz Group (www.edanzediting.com/ac) for editing a draft of this manuscript.

\section{Literature Cited}

Černý, R., M. Kubů and D. Kubička; “The Effect of Oxygenates Structure on Their Deoxygenation over USY Zeolite," Catal. Today, 204 46-53 (2013)

Chang, C.-C. and S.-W. Wan; "China's Motor Fuels from Tung Oil," Ind. Eng. Chem., 39, 1543-1548 (1947)

Corma, A., G. W. Huber, L. Sauvanaud and P. O'Connor; "Biomass to Chemicals: Catalytic Conversion of Glycerol/Water Mixtures into Acrolein, Reaction Network," J. Catal., 257, 163-171 (2008)

Doronin, V. P., O. V. Potapenko, P. V. Lipin and T. P. Sorokina; "Catalytic Cracking of Vegetable Oils and Vacuum Gas Oil,” Fuel, 106, 757-765 (2013)

Dupain, X., D. J. Costa, C. J. Schaverien, M. Makkee and J. A. Moulijn; "Cracking of a Rapeseed Vegetable Oil under Realistic FCC Conditions," Appl. Catal. B, 72, 44-61 (2007)

Gates, B. C., J. R. Katzer and G. C. A. Schuit; Chemistry of Catalytic Processes, McGraw-Hill, New York, U.S.A. (1979)

Hosokai, S., K. Matsuoka, K. Kuramoto, S. Matsuda and Y. Suzuki; "System Analysis of in situ Bio-Oil Hydrodeoxygenation," J. Chem. Eng. Japan, 47, 549-554 (2014)

Huber, G. W. and A. Corma; "Synergies between Bio- and Oil Refineries for the Production of Fuels from Biomass," Angew. Chem. Int. Ed., 46, 7184-7201 (2007)

Inaba, M., K. Murata, I. Takahara and Y. Liu; "Catalytic Fast Pyrolysis of Eucalyptus Using Zeolite," J. Chem. Eng. Japan, 47, 345-351 (2014)

Kubičková, I. and D. Kubička; "Utilization of Triglycerides and Related Feedstocks for Production of Clean Hydrocarbon Fuels and Petrochemicals: A Review," Waste Biomass Valoriz., 1, 293-308 (2010)

Kwon, E. E., H. Yi and J. Park; "Transesterification of Used Vegetable Oil by Magnesium Slag as Heterogeneous Catalyst (MgO-CaO/ $\left.\mathrm{Al}_{2} \mathrm{O}_{3}\right)$," J. Chem. Eng. Japan, 45, 850-856 (2012)

Melero, J. A., M. M. Clavero, G. Calleja, A. Garcia, R. Miravalles and T. Galindo; "Production of Biofuels via the Catalytic Cracking of Mixtures of Crude Vegetable Oils and Nonedible Animal Fats with Vacuum Gas Oil," Energy Fuels, 24, 707-717 (2010)

Potapenko, O. V., V. P. Doronin, T. P. Sorokina, O. V. Krol and V. A. Likholobov; "A Study of Intermolecular Hydrogen Transfer from Naphthenes to 1-Hexane over Zeolite Catalysts," Appl. Catal. A, 516, 153-159 (2016)

Shimada, I., R. Imai, Y. Hayasaki, H. Fukunaga, N. Takahashi and T. Takatsuka; "Increasing Octane Value in Catalytic Cracking of $n$ Hexadecane with Addition of *BEA Type Zeolite," Catalysts, 5, 703-717 (2015a)

Shimada, I., K. Takizawa, H. Fukunaga, N. Takahashi and T. Takatsuka; "Catalytic Crackig of Polycyclic Aromatic Hydrocarbons with Hydrogen Transfer Reaction," Fuel, 161, 207-214 (2015b)

Shimada, I., S. Kato, N. Hirazawa, Y. Nakamura, H. Ohta, K. Suzuki and T. Takatsuka; "Deoxygenation of Triglycerides by Catalytic Cracking with Enhanced Hydrogen Transfer Activity," Ind. Eng. Chem. Res., 56, 75-86 (2017)

Sinthupinyo, P., H. Habaki and R. Egashira; "Factors Influencing the Use of Various Low-Value Oils in Biodiesel Production," J. Chem. Eng. Japan, 43, 214-223 (2010)

Sternberg, J. C., W. S. Gallaway and D. T. L. Jones; “The Mechanism of 
Response of Flame Ionization Detectors," Gas Chromatography, N Brenner, J. E. Gallen and M. D. Weiss eds., pp. 231-268, Academic Press, New York, U.S.A. and London, U.K. (1962)

Taufiqurrahmi, N. and S. Bhatia; "Catalytic Cracking of Edible and Non-Edible Oils for the Production of Biofuels," Energy Environ.
Sci., 4, 1087-1112 (2011)

Tsuchiya, Y., Y. Kaneki and Y. Yamakoshi; " $\mathrm{H}_{2} \mathrm{SO}_{4} / \mathrm{CaO}-$ Catalyzed Process for Biodiesel Production from High Acid Value Jatropha curcas Crude Oil," J. Chem. Eng. Japan, 44, 529-533 (2011) 